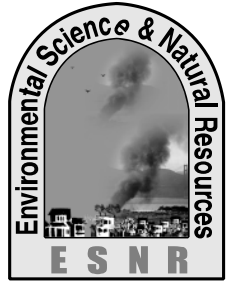

\title{
Hospital Waste Generation and Management in Mymensingh Municipality
}

\section{A. Islam, M. N. Mobin, M. A. Baten*, M. A. M. Hossen and M. J. Islam}

Department of Environmental Science, Bangladesh Agricultural University, Mymensingh

${ }^{1}$ Department of Development Studies, Bangladesh University of Professionals, Dhaka

*Corresponding author: baten_envsc@yahoo.com

Abstract

The study was conducted on hospital waste generation in Mymensingh municipality and also its management technique. Data was collected through questionnaire interview from local residents, superintendents, nurses, observation and secondary sources. The results revealed that wastes are collected every alternative day and though sometime in irregular basis. Hospital wastes causes different health hazards like bad smell, infestation of animals, diarrhoea, skin diseases etc. due to irregular collection, unsafe handling, disposal, storage, transportation and finally dumped with municipal wastes. Shortage of dustbin is common in every hospitals and clinics in Mymensingh municipality. The study also revealed that $1500-2000 \mathrm{~kg}$ wastes were generated per day in Mymensingh municipality area in which 25\% infectious and $75 \%$ non- infectious. These huge amount of wastes could be treated or disposed by the process like incineration, deep-burial, local autoclaving, micro waving, disinfections destruction \& drugs disposal in secured landfills, chemical treatment etc.

Key words: Biomedical waste management, Hazardous waste, Health care unit

\section{Introduction}

Hospital waste management has recently emerged as an issue of major concern not only to hospitals, nursing home authorities but also to the environment. The hospital wastes generated from health care units depend upon a number of factors such as waste management methods, type of health care units, occupancy of healthcare units, specialization of healthcare units, ratio of reusable items in use, availability of infrastructure and resources etc. (Mandal and Dutta, 2009). The safe disposal of hospital waste has been ignored in Bangladesh. Hospital waste is a source of contamination and pollution to both humans and the environment. Hospital waste is capable of causing diseases and illnesses to people, either through direct contact or indirectly by contaminating soil, groundwater, surface water and air. Wind from these dumps can also carry pathogens and hazardous materials. Hospital waste therefore, poses a risk to individuals, communities, and the environment if not carefully handled (Akter et al., 1998). There has been little research done on Hospital waste disposal in Bangladesh. A survey, conducted by Rashid et al, (2006) on Hospital Waste Disposal in Dhaka City, found that the government hospitals placed all waste in open dustbins for up to two days. Other hospitals left their waste outside in open dustbins for two to three days before a municipal truck would remove them. Used syringes and other medical and clinical waste were sold for Tk. 20/kg at most hospitals and clinics visited. Rashid et al, (2006) concluded that there was a lack of knowledge and interest in safe waste disposal by most health workers and an absence of a budget to effectively implement safe waste disposal. Kazi et al, (1997) also conducted a study on hospital waste in Dhaka and recommended several steps to improve hospital waste management in Bangladesh.
The problem is getting worse with the increasing number of hospitals, clinics and diagnostic laboratories in the municipality. The rapid increase of private hospitals, clinics, diagnostic laboratories etc. in the Mymensingh municipality exerts a tremendous impact on human health and ecology. More than 20 clinics and hospitals exist in the Mymensingh municipality. Among these, 9 clinics and hospital have been studied which are producing hospital waste in a large quantity now-a-days. Considering these consequences, the study was conducted with the following objectives ; i) to quantify the amount of solid wastes generated by each HCE and ii) to identify the current hospital waste management practices (e.g. storage, collection, transportation and disposal ) within the hospital premises.

\section{Materials and Methods}

Mymensingh is one of the districts of Dhaka division, Bangladesh and is bordered on the North by Meghalaya state of India and Garo Hills, on the South by Gazipur district, on the East by districts of Netrokona and Kishoreganj and on the West by districts of Sherpur, Jamalpur and Tangail. Mymensingh town is the district headquarters. Mymensingh sadar is located at $24^{\circ} 02^{\prime} 31^{\prime \prime}$ to $25^{\circ} 25^{\prime} 56^{\prime \prime}$ North latitudes and between $89^{\circ} 39^{\prime}$ to $91^{\circ} 15^{\prime} 35^{\prime \prime}$ East longitude. It has 104,567 units of household and its total area is $388.45 \mathrm{~km}^{2}$. The River Brahmaputra just crosses the section of Mymensingh. The data of hospital waste of Mymensingh municipality was collected by investigation of the waste throwing normal dustbins, drains and open areas. The primary data was collected from various sources and in various ways. The tool which was used to collect the primary data is questionnaire schedule from superintendent of the Hospital, Clinics and other Diagnostic centre. Different data about the hospital 
wastes were collected through field level inventory, questionnaire surveys and interviews with doctors, nurses, superintendent, Resident Medical Officer and Civil Surgeon in hospitals and in-depth interviews with different respondents allow a greater depth of understanding of the waste management system in the study area.

The nurses, waste labours and workers were questioned through for measuring the daily waste amounts, waste types and waste source denotation. For the investigation of the municipality waste sources and waste problems, some locations were observed regularly by following a weeklong duration.

\section{Results and Discussion}

From the investigation we have to classify different three respondent groups are shown in following tables.

Table 1. Age Distribution of the Respondent

\begin{tabular}{|c|c|}
\hline Age categories ( Year) & Percentage ( \% ) \\
\hline Young ( $10-30)$ & 27.68 \\
\hline Middle ( $31-50)$ & 47.21 \\
\hline Old ( 51-70) & 25.11 \\
\hline Total & 100 \\
\hline
\end{tabular}

Table 2. Education of the Respondent

\begin{tabular}{|c|c|}
\hline Educational status & Percentage ( \%) \\
\hline Primary ( 1-5 ) & 9.13 \\
\hline SSC (6-10) & 18.33 \\
\hline HSC (11- 12) & 33.15 \\
\hline Graduate ( 13- 16) & 22.20 \\
\hline Masters ( 17- 18) & 17.19 \\
\hline Total & 100 \\
\hline
\end{tabular}

The study finds that total $1500-2000 \mathrm{~kg} \mathrm{day}^{-1}$ waste materials have been measured in Mymensingh municipality where the total wastes generated from Dhaka City were $3000-4000 \mathrm{~kg} \mathrm{day}^{-1}$ (Rashid et al., 2006). The waste generation of major hospitals and

\section{Percentage of Infectious Agents}

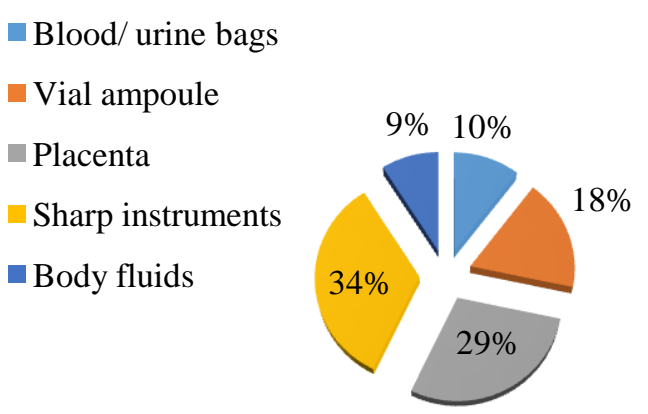

clinics and their types is given in table 4 . Mymensingh Medical College and Hospital is the biggest government owned hospital in Mymensingh municipality.

Table 3. Category of the different Respondents

\begin{tabular}{|c|c|}
\hline Category & Percentage ( \% ) \\
\hline Daily labor & 28.57 \\
\hline Service holder & 12.29 \\
\hline Student & 21.43 \\
\hline House wife & 14.28 \\
\hline Tokai & 23.43 \\
\hline Total & 100 \\
\hline
\end{tabular}

During the field survey, various hospital wastes was observed such as pathological wastes, textile stained with blood, cotton pads, used syringes, broken bottles and glass, paper, cans and other metals, vegetables/rubbish and sharp instruments ( syringe- needles, surgical blades and blood lancets) etc. Some of the wastes are blood stained. All the HCE produce used syringes, broken bottles and glass, textile stained with blood and papers. The Study measured about $75 \%$ was non- infectious wastes and about $25 \%$ was infectious wastes per day.

\section{Percentage of Hospital Wastes}

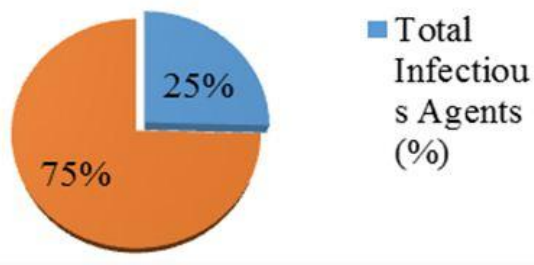

Fig. 1. Percentage of Hospital Waste

\section{Percentage of Non-infectious Agents}

Kitchen

Cotton
bandage
Saline bags
Others

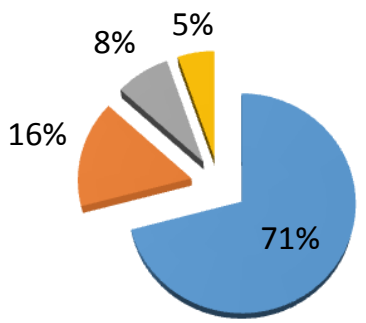

Fig. 2. Percentage of infectious and non-infectious agents 
Table 4. Proportion of different hospital wastes in Mymensingh municipal area

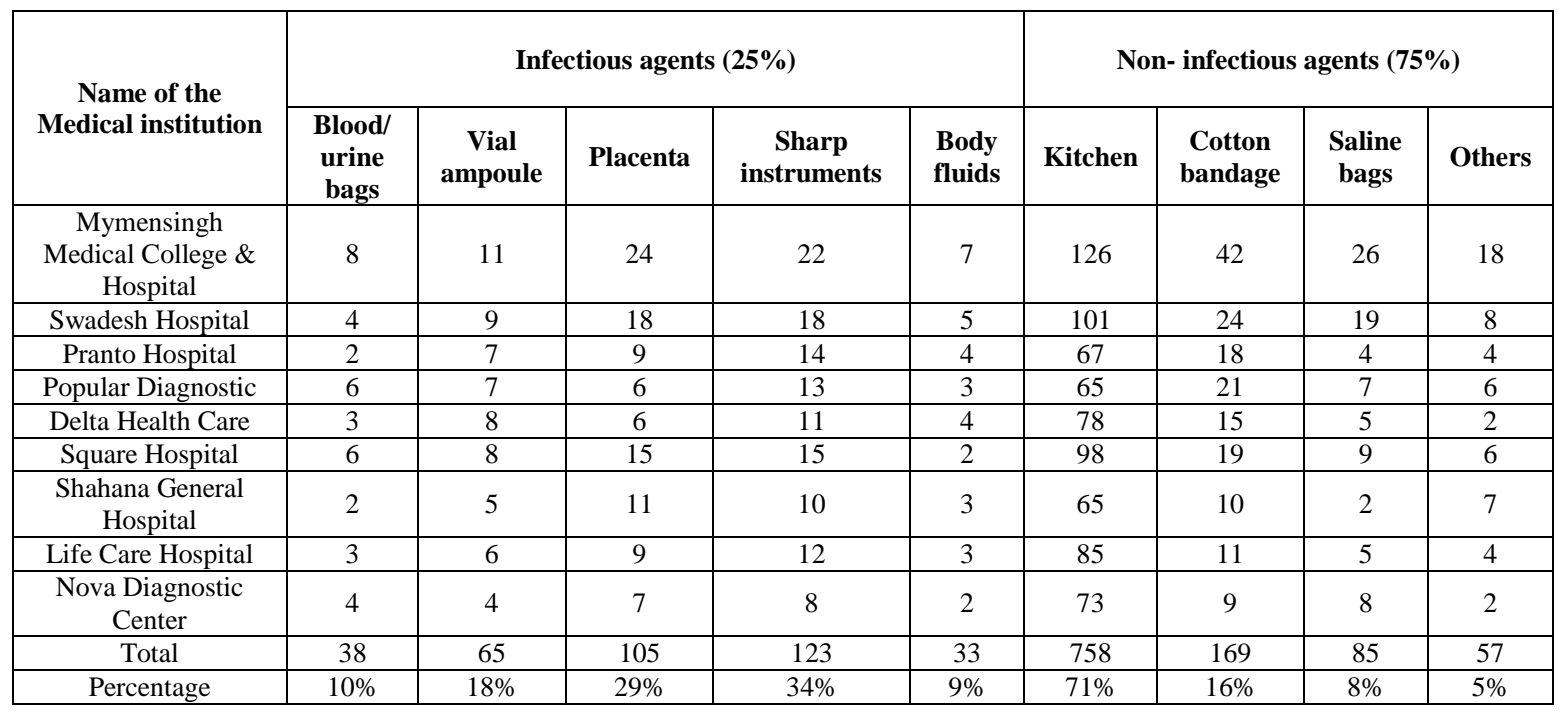

From the (Fig. 1), we can see that among the total hospital waste, $25 \%$ are infectious agents and $75 \%$ are non-infectious agents. Among the infectious agents sharp instruments are representing higher amount of infectious agents with $34 \%$ (Fig. 2). All the institution which are studied of either governmental or non-governmental like Mymensingh Medical College and Hospital, Swadesh Hospital, Pranto Hospital, Popular Diagnostic, Delta Health Care, Square Hospital,
Shahana General Hospital, Life Care Hospital. Nova Diagnostic Center, representing the good amount of sharp instruments. Among other infectious agents, placenta takes second place with $29 \%$, vial ampoule takes $3^{\text {rd }}$ place with $18 \%$, blood/urine bags and body fluids take place of later on with $10 \%$ and $9 \%$ of total infectious agents are shown in Fig. 2. The amounts of infectious agents in different hospital and clinics are specified in Table 4.

Table 5. Management techniques of medical waste

\begin{tabular}{|c|c|c|}
\hline Option & Treatment and disposal & Waste category \\
\hline Cat. No. 1 & Incineration / deep burial & Human Anatomical Waste (human tissues, organs, body parts) \\
\hline Cat. No. 2 & Incineration / deep burial & $\begin{array}{l}\text { Animal Waste Animal tissues, organs, Body parts carcasses, bleeding } \\
\text { parts, fluid, blood and experimental animals used in research, waste } \\
\text { generated by veterinary hospitals / colleges, discharge from hospitals, } \\
\text { animal houses) }\end{array}$ \\
\hline Cat. No. 3 & $\begin{array}{l}\text { Local autoclaving/ micro waving/ } \\
\text { incineration }\end{array}$ & $\begin{array}{l}\text { Microbiology \& Biotechnology waste (wastes from laboratory } \\
\text { cultures, stocks or specimens of micro-organisms live or attenuated } \\
\text { vaccines, human and animal cell culture used in research and } \\
\text { infectious agents from research and industrial laboratories, wastes } \\
\text { from production of biological, toxins, dishes and devices used for } \\
\text { transfer of cultures) }\end{array}$ \\
\hline Cat. No. 4 & $\begin{array}{l}\text { Disinfections (chemical treatment } \\
\text { autoclaving/ micro waving and } \\
\text { mutilation shredding }\end{array}$ & $\begin{array}{l}\text { Waste Sharps (needles, syringes, scalpels blades, glass etc. that may } \\
\text { cause puncture and cuts. This includes both used \& unused sharps }\end{array}$ \\
\hline Cat. No. 5 & $\begin{array}{l}\text { Incineration / destruction \& drugs } \\
\text { disposal in secured landfills }\end{array}$ & $\begin{array}{l}\text { Discarded Medicines and Cytotoxic drugs (wastes comprising of } \\
\text { outdated, contaminated and discarded medicines) }\end{array}$ \\
\hline Cat. No. 6 & $\begin{array}{l}\text { Incineration, autoclaving/micro } \\
\text { waving }\end{array}$ & $\begin{array}{l}\text { Solid Waste (Items contaminated with blood and body fluids } \\
\text { including cotton, dressings, soiled plaster casts, line beddings, other } \\
\text { material contaminated with blood) }\end{array}$ \\
\hline Cat. No. 7 & $\begin{array}{l}\text { Disinfections by chemical } \\
\text { treatment autoclaving/ micro } \\
\text { waving and mutilation shredding. }\end{array}$ & $\begin{array}{l}\text { Solid Waste (waste generated from disposable items other than the } \\
\text { waste sharps such as tubing, catheters, intravenous sets etc.) }\end{array}$ \\
\hline Cat. No. 8 & $\begin{array}{l}\text { Disinfections by chemical } \\
\text { treatment and discharge into drain }\end{array}$ & $\begin{array}{l}\text { Liquid Waste (waste generated from laboratory \& washing, cleaning, } \\
\text { house-keeping and disinfecting activities) }\end{array}$ \\
\hline Cat. No. 9 & Disposal in municipal landfill & Incineration Ash (ash from incineration of any bio-medical waste) \\
\hline Cat. No. 10 & $\begin{array}{l}\text { Chemical treatment \& discharge } \\
\text { into drain for liquid \& secured } \\
\text { landfill for solids }\end{array}$ & $\begin{array}{l}\text { Chemical Waste (chemicals used in production of biological, } \\
\text { chemicals, used in disinfect ion, as insecticides, etc). }\end{array}$ \\
\hline
\end{tabular}


Among the total non-infectious agents, kitchen wastes contain the higher amount of non-infectious hospital waste with $71 \%$. Others non-infectious wastes are cotton bandage, saline bags and others which representing $16 \%, 8 \%$ and $5 \%$ of total noninfectious agents. The amounts of non-infectious agents in different hospital are also specified in the Table 4. In all hospitals, pharmaceutical waste and pressurized containers are disposed along with the general waste. Liquid pharmaceutical waste is poured into the drains along with liquid chemical waste. Most of the HCE do not have plastic bags and strong plastic containers for infectious waste in accordance with the WHO guideline (WHO, 2001). According to, The Bio Medical Waste (Management and Handling) Rules, 1998, management techniques of different hospital wastes with their treatment and disposals are given in the above in the Table 5.

\section{Conclusions}

From the investigation, hospital wastes should be classified according to their source, typology and risk factors associated with their handling, storage and ultimate disposal. The segregation of waste at source is the key step and reduction, reuse and recycling should be considered in proper perspectives. We need to consider innovative and radical measures to clean up the distressing picture of lack of civic concern on the part of hospitals and slackness in government implementation of bare minimum of rules, as waste generation particularly biomedical waste imposes increasing direct and indirect costs on society. The challenge before us, therefore, is to scientifically manage growing quantities of hospital waste that go beyond past practices. If we want to protect our environment and health of community we must sensitize ourselves to this important issue not only in the interest of health managers but also in the interest of community. In order to arrange a proper and systematic waste management, the following recommendations may be considered; i) avoid the following risk of health effect from the wastes, it needs to formulate proper policy regarding this issue, ii) hospital wastes are needed to be segregated separately, according to its characteristics, at the point of generation, iii) a remedial measure with the installation of an environment friendly incinerator in the city.

\section{References}

Aktet, N.; Acott, R. E. and Chowdhury, S. A. 1998. Medical waste disposal at BRAC health centres: an environmental study. BRAC Research, Research and Evaluation Division, 75 Mohakhali C/A, Dhaka 1212.

JICA (Japan International Cooperation Agency). 2004. Clean Dhaka Master Plan. Progress report, JICA: Dhaka.

Kazi, N. M. 1997. Waste Management in Dhaka. Bangladesh Environmental Newsletter, vol.8, No.4. Bangladesh Center for Advanced Studies (BCAS), Dhaka, Bangladesh.

Mandal, S. K. and Dutta, J. 2009. Integrated BioMedical Waste Management Plan for Patna City, Institute of Town Planners, India Journal 6-2: 01-25.

Rashid, S. 1996. Medical waste disposal in Dhaka city: A survey. Unpublished thesis. NorthSouth University. Dhaka, Bangladesh.

WB (World Bank). 1991. Environmental assessment sourcebook. Volume II: Sectoral Guidelines. World Bank Technical Paper No.140, Environmental Department, The World Bank. Washington, DC, USA.

WHO (World Health Organisation). 2001. Healthcare Waste Management: Rapid Assessment Tool for Country Level. World Health Organization: Geneva. 